\title{
A CULTURA POPULAR COMO ELEMENTO PARA INSERÇÃO DA LEI No 11.645/08 NO CURRÍCULO ESCOLAR
}

\section{A POPULAR CULTURE AS ELEMENT TO INSERT No 11.645/08 IN SCHOOL CURRICULUM}

\section{LA CULTURA POPULAR COMO ELEMENTO PARA INSERCIÓN DA LEY N ${ }^{\circ}$ 11.645/08 EN EL CURRICULUM DE LA ESCUELA}

\author{
Heridan de Jesus Guterres Pavão Ferreira \\ Professora Mestra da Universidade Federal do Maranhão, \\ Campus São Bernardo (UFMA). \\ hguterres@hotmail.com \\ Rayron Lennon Costa Sousa \\ Professor Bolsista do Programa de Formação de Professores para a Educação Básica (PROEB) da \\ Universidade Federal do Maranhão, Campus São Bernardo (UFMA). \\ rayronsousa@hotmail.com \\ Wheriston Silva Neris \\ Professor Doutor da Universidade Federal do Maranhão, \\ ampus Bacabal (UFMA). \\ wheristoneris@yahoo.com.br
}

RESUMO: A Lei n 11.645/08 dispõe acerca da inserção da história e cultura africana, afro-brasileira e indígena no currículo escolar e constitui-se um marco, ao considerar-se que, por muito tempo, negros e índios foram desconsiderados ou concebidos pela escola, de forma pejorativa ou em posição de subserviência. Este artigo, fruto de um projeto de extensão desenvolvido em uma unidade da Universidade Federal do Maranhão, descreve alguns aspectos pertinentes às temáticas sugeridas pela lei supracitada, em sala de aula. Com base nas atividades desenvolvidas no âmbito do projeto, a partir da observação participante, constatou-se que a cultura popular torna-se, então, uma estratégia a ser adotada para inserção da Lei no 11.645/08, nas escolas brasileiras e maranhenses, em razão de sua riqueza e diversidade, possibilitando um ensino contextualizado e significativo.

PALAVRAS-CHAVE: Lei n $11.645 / 08$. Ensino. Escola. Cultura popular. Cultura popular maranhense.

ABSTRACT: The Law $n^{\circ} 11.645 / 08$ has concerning the insertion of African history and culture, african-Brazilian and indigenous in the school curriculum and constitutes a milestone when considering that for a long time, blacks and Indians were disregarded or designed by the school, so derogatory or subservient position. This article, the result of an extension project developed by one of the Federal University of Maranhão describes some aspects about the themes of the law in the classroom. Based on the activities carried out under the project it was found that the popular culture then becomes a strategy to be adopted for insertion of Law $n^{\circ} 11.645 / 08$ in Brazilian schools because of its richness and diversity, providing a contextualized education and significant.

KEYWORDS: Law n 11.645/08. Education. School. Popular culture. Maranhão popular culture.

RESUMEN: La Ley $n^{\circ}$ 11.645/08 relativo a la inserción de la historia y la cultura africana, afro-brasileña e indígena en el currículo de las escuelas y constituye un hito al considerar que, durante mucho tiempo, los negros y los indios se tuvieron en cuenta o diseñados por la escuela, en posición despectivo o servil. Este artículo es el resultado de un proyecto de extensión desarrollado por uno de la Universidad Federal del Maranhão describe algunos aspectos relacionados con la aplicación de la ley en las clases. Con la base de las actividades realizadas en el marco del proyecto se encontró que la cultura popular se convierte en una estrategia que se adopte para la inserción de la Ley $n^{\circ} 11.645 / 08$ en las escuelas brasileñas, debido a su riqueza y diversidad, ofrecer una educación contextualizada y significativa.

PALABRAS CLAVE: Ley nº 11.645/08. Enseñanza. Cultura Popular. 
A CULTURA POPULAR | Heridan de Jesus G. P. Ferreira, Rayron Lennon C. Sousa e Wheriston S. Neris

\section{1 | INTRODUÇÃO}

A escola brasileira, nos dias atuais, vem sendo questionada em razão de não cumprir sua função social, função esta relacionada à formação integral dos cidadãos, em uma perspectiva que estes utilizem os conhecimentos nela trabalhados, empregando-os em diferentes contextos de sua vida. De acordo com Morin (2001), cabe à escola socializar o saber sistematizado, a fim de preparar os sujeitos que dela fazem parte para o exercício da cidadania.

Tais questionamentos têm feito com que caminhos sejam buscados, para superação da crise que assola a escola, crise esta que se evidencia pela ausência de um projeto político-pedagógico eficiente, que traga em seu bojo conteúdos significativos, contextualizados ao tempo e espaço dos sujeitos sociais que integram a escola. buscando, em elementos e temas até então pouco considerados, caminhos para superação dos problemas que afloram em seu contexto, visando à promoção do diálogo entre o particular e o coletivo, bem como entre as singularidades e as diversidades no contexto da escola.

Entre os temas que mais vêm sendo discutidos está a questão racial que até então foi pouco considerada ou tratada, a partir de uma visão estereotipada e preconceituosa, resultado de uma educação predominantemente eurocêntrica que caracterizou o ensino no Brasil. O modelo de ensino pautado no eurocentrismo deixou suas marcas na educação, marcas estas que, a despeito de ter passado um tempo substancial, ainda se fazem presentes e continuam a estigmatizar e segregar sujeitos e conteúdos (HASENBALG; SILVA, 1990).

A despeito disso, a chamada universalização da educação potencializou, nas últimas décadas, o ingresso de sujeitos que antes eram considerados invisíveis ou desconsiderados enquanto protagonistas da construção do próprio conhecimento, o que levou ao aumento das discussões a respeito do que deve ser trabalhado no âmbito do currículo, questionando esse currículo que, ao mesmo tempo em que é colonizado, constitui-se colonizador (MOREIRA; SILVA, 2002).

Considera-se assim, que os sujeitos sociais que coabitam a escola exigem propostas mais dialógicas que permitam o protagonismo e autoria, sendo participantes ativos da própria formação. Entre essas propostas e, como fruto da organização de diferentes movimentos da sociedade organizada, foi sancionada, em 2003, a Lei $n^{\circ}$ 10.639. Cinco anos depois, em 2008, uma nova Lei foi sancionada, a de $\mathrm{n}^{\circ} 11.645$.

Ainda que se observe certo avanço, especialmente a partir da promulgação dessas duas leis que tornam obrigatório o ensino de história e cultura afro-brasileira e indígena no currículo escolar, muito ainda há que se avançar em termos quantitativos e qualitativos, a fim de que a escola cumpra de fato com sua tarefa de educar para a diversidade, condição precípua para a formação cidadã.

Este trabalho busca evidenciar os elementos da cultura popular dos quais a escola pode utilizar para dar o tratamento adequado para a questão racial, enfatizando-se o papel da cultura popular, especialmente da cultura popular maranhense, na implementação da Lei $n^{\circ} 11.645 / 08$ no currículo escolar. O trabalho faz uma análise descritiva de uma experiência docente em escolas públicas.

Trata-se de um estudo de natureza qualitativa (BARDIN, 2011), caracterizado como trabalho de campo (MINAYO, 2010). Foi desenvolvido em 4 (quatro) escolas públicas do município de São Bernardo/MA: Instituto Educacional Cônego Nestor de Carvalho Cunha (IECNCC), Centro de Ensino Déborah Correia Lima (CEMDCL), Centro de Ensino Médio Dr. Henrique Couto (CEMDHC), Escola Municipal Bernardo Alves Rodrigues (EMBAR), com um total de 40 (quarenta) profissionais envolvidos entre gestores, professores e representantes dos discentes. 
A metodologia utilizada foi a descritiva, discorrendo-se sobre uma atividade realizada no contexto de um projeto de extensão desenvolvido no Curso de Linguagens e Códigos da Universidade Federal do Maranhão, no município de São Bernardo/MA. O objetivo foi promover a interação entre universidade e comunidade, assim como a efetivação da história e cultura indígena e afro-brasileira na sala de aula, ancorando-se nos pressupostos de Paulo Freire (1963), Santos (2006), Moreira e Silva (2002), Arroyo (2011), dentre outros teóricos que discutem um currículo voltado para a diversidade e valorização da cultura popular. Esse currículo deve ter como premissa as situações vivenciadas entre os atores que permeiam o contexto escolar e as relações sociais por eles vivenciadas.

De acordo com Sacristán (1995, p. 86-87), o currículo

[...] tem que ser entendido como a cultura real que surge de uma série de processos, as decisões prévias acerca do que se vai fazer no ensino, as tarefas acadêmicas reais que são desenvolvidas, a forma como a vida interna das salas de aula e os conteúdos de ensino se vinculam com o mundo exterior, as relações grupais, o uso e o aproveitamento de materiais, as práticas de avaliação, etc.

Nesse contexto, verifica-se a indissociabilidade entre o contexto social e o que é ensinado e aprendido na escola. Assim sendo, o trabalho focaliza, ainda que sucintamente, as Leis de $\mathrm{n}^{\circ}$ 10.639/03 e n 11.645/08, a educação para as relações étnico-raciais que são o foco do projeto desenvolvido em São Bernardo/MA, além de aspectos relacionados à questão racial no ambiente escolar e à inserção do tema, tomando como viés a cultura popular maranhense.

\section{2 | BREVES CONSIDERAÇÕES SOBRE AS LEIS N 10.639/03 E Nº 11.645/08}

A Lei $n^{\circ} 10.639$, sancionada em 9 de janeiro de 2003, tornou obrigatória a inserção da história e cultura africana e afro-brasileira no currículo escolar do Ensino Fundamental e Médio das escolas brasileiras, oportunizando uma visibilidade até então negada aos negros e negras, ainda que essa visibilidade ocorra tardiamente, alterando a LDB $n^{\circ}$ 9.394/96, a qual estabelece as diretrizes e bases da educação nacional, para incluir no currículo oficial da Rede de Ensino a obrigatoriedade da temática "História e Cultura Afro-Brasileira, e dá outras providências", como segue:

Art. $1^{\circ}$ - A Lei $n^{\circ}$ 9.394/1996 passa a vigorar acrescida dos seguintes Arts. 26-A, 79-A e 79-B:

Art. 26-A - Nos estabelecimentos de ensino fundamental e médio, oficiais e particulares, torna-se obrigatório o ensino sobre História e Cultura Afro-Brasileira.

$\S 1^{\circ} \mathrm{O}$ conteúdo programático a que se refere o caput deste artigo incluirá o estudo da História da África e dos Africanos, a luta dos negros no Brasil, a cultura negra brasileira e o negro na formação da sociedade nacional, resgatando a contribuição do povo negro nas áreas social, econômica e política pertinentes à História do Brasil.

$\S 2^{\circ}$ Os conteúdos referentes à História e Cultura Afro-Brasileira serão ministrados no âmbito de todo o currículo escolar, em especial nas áreas de Educação Artística e de Literatura e História Brasileiras. (BRASIL, 2003, grifo nosso).

\footnotetext{
1 O Curso de Linguagens e Códigos é uma licenciatura interdisciplinar única no Brasil, vinculada à Universidade Federal do Maranhão, Campus de São Bernardo. O currículo do Curso se propõe à formação de docentes para atuarem nas áreas de língua portuguesa, língua inglesa, língua espanhola, artes visuais e música, nas séries finais do Ensino Fundamental, com possibilidade de habilitação em língua portuguesa ou música, atuando no Ensino Médio.
} 
Observa-se desse modo que a lei deixa nítida a obrigatoriedade do ensino de conteúdos sobre a matriz negra africana na constituição da sociedade brasileira, inserindo-a no currículo escolar, apontando as áreas de História, Literatura e Educação Artística como as disciplinas que devem trabalhar tais conteúdos de modo precípuo, sem, contudo, deixar de considerar as demais áreas do conhecimento, pois, conforme preconiza a lei, tais conteúdos devem ser de competência de todas as áreas de conhecimento, tanto no Ensino Fundamental como no Ensino Médio.

Assim sendo, o ensino da História e Cultura Afro-brasileiras e africanas deixa de estar tão somente no âmbito da vontade individual dos educadores que, de forma isolada, abordavam o tema na sala de aula, via de regra, sem muita profundidade, restringindo-se aos livros didáticos, especialmente os de História que, por sua vez, mostraram o negro em posição de inferioridade ou sob estereótipos.

O objetivo principal para inserção da Lei é o de divulgar e produzir conhecimentos, bem como atitudes, posturas e valores que eduquem cidadãos quanto à pluralidade étnico-racial, tornando-os capazes de interagir objetivos comuns que garantam respeito aos direitos legais e valorização de identidade cultural brasileira e africana, como outras que, direta ou indiretamente, contribuíram e ainda contribuem para a formação da identidade cultural brasileira (BRASIL, 2003).

Posteriormente, em 2008, a Lei $n^{\circ} 10.639 / 03$ foi modificada pela Lei $n^{\circ} 11.645 / 08$ que insere, além da história e cultura africana e afro-brasileira, a história e cultura indígena, fazendo jus à contribuição dos povos negros e indígenas na formação do Brasil, colocando-os como protagonistas da história da formação do povo brasileiro e não como mero coadjuvantes como até então vinham sendo mostrados (BRASIL, 2008).

Trabalhar tais conteúdos nas escolas tem sido uma batalha entre o antigo e o novo, realidades diferentes para contextos contrastantes como os dos livros didáticos que os alunos e alunas têm acesso nas escolas. Um dos principais desafios, porém, é inserir a temática a partir de um olhar que considere a diversidade como elemento a possibilitar o acesso a diferentes culturas e saberes, partindo-se para tanto, do local para o global.

\section{3 | CONSIDERAÇÕES SOBRE A QUESTÃO RACIAL NO CONTEXTO ESCOLAR}

Os fundamentos teóricos e os princípios pedagógicos norteadores da discussão suscitada no desenvolvimento do projeto trabalhado em São Bernardo se inscrevem em pelo menos três campos de discussão: em primeiro lugar, o da discussão sobre o racismo, o preconceito e a discriminação social no Brasil; o segundo engloba um conjunto de pesquisas que têm se debruçado sobre o tema do tratamento da diversidade cultural no âmbito escolar; o terceiro envolve o próprio desafio de orientar ações no espaço escolar e universitário conduzidas pelo princípio da indissociabilidade entre ensino, pesquisa e discussão para enfrentamento desses temas.

No primeiro campo mencionado, encontram-se diversas pesquisas dedicadas a discutir a construção do racismo e do preconceito e a prática de discriminações decorrentes da incapacidade de assimilação e compreensão das diferenças (BANDEIRA; BATISTA, 2002). O tema adquire particular relevância em sociedades hierarquizadas, como a brasileira, nas quais se atribui um valor negativo à condição da diferença (cor, raça, sexo, classe), e que historicamente serviu (e ainda serve) de critério para negação de direitos e para instauração de diferentes modalidades de violência, tanto de ordem material quanto simbólica.

Não é exagerado dizer que, nas ciências sociais, como um todo de uma visão que focava mais as diferenças em termos de classe e posição no sistema de relações econômicas, em uma clara opção pela macro escala de explicação social, lentamente foi se construindo uma nova sensibilidade para a experiência particular de violência, discriminação e poder, que permeia e atravessa 
A CULTURA POPULAR | Heridan de Jesus G. P. Ferreira, Rayron Lennon C. Sousa e Wheriston S. Neris

as diferentes camadas sociais em suas relações mais individualizadas e microscópicas. Além da disputa de poder levada a cabo nos grandes cenários, o olhar direcionou-se, então, para os bastidores onde se podem observar de forma mais refinada e com maiores detalhes, as diferenças, os particularismos e as singularidades (DOSSE, 2003).

Essa percepção também foi alimentada pela mobilização de diversos movimentos sociais (negros, feministas, terceiro-mundistas, religiosos) que recolocaram no centro da arena política a questão dos direitos socioculturais, do respeito à diferença e à alteridade como parte constitutiva dos próprios direitos humanos. Diversas mobilizações e manifestações declarando o orgulho de ser negro, homossexual, mulher, indígena não apenas colocaram a nu, a questão da violência e a existência de preconceitos e discriminações que vedavam a inserção em diversas esferas da sociedade, como também preencheram as agendas de reflexão nas ciências humanas. Houve todo um longo esforço por ressignificar atribuições identitárias vistas como negativas, atribuindo a esses termos uma dimensão positiva e politicamente informada (CUNHA JÚNIOR, 1996). Ao que tudo indica, no Brasil, o movimento negro exerceu um papel fundamental tanto em relação às demandas da população negra, como até mesmo de outros movimentos sociais, no sentido de pressionar o ordenamento jurídico, buscando tratar a questão da diferença.

Essa pressão no espaço jurídico se faz sentir desde, pelo menos, a Lei Afonso Arinos (BRASIL, 1951), que foi a pioneira no Brasil a considerar como contravenção qualquer tipo de preconceito de raça e cor. Cada nova alteração no contexto legislativo e a própria redefinição contínua dos conceitos fundamentais da filosofia política e jurídica do Estado têm sido o resultado de árduas lutas da sociedade civil organizada. Nesse sentido e tocando em uma questão que interessa mais diretamente à discussão suscitada, a extraordinária promulgação da Lei $n^{0}$ 10.639/03 (que inclui a história da África e dos afrodescendentes nos currículos escolares) e da Lei n 11.645/08, (que inclui a cultura e a história dos povos indígenas) (BRASIL, 2003, 2008), as quais alteraram, como já mencionado anteriormente, dispositivos da Lei de Diretrizes e Bases da Educação Nacional (LDB) n 9.394/96, e que tornaram obrigatório o ensino da história e cultura afro-indígena brasileira, nos estabelecimentos de ensino das redes pública e particular do país, encontram seu sentido nessa série de lutas ordinárias e anteriores, que constituíram as bases de legitimidade para esse novo produto jurídico.

$\mathrm{Na}$ realidade, essas leis vêm modificar o tratamento da questão racial que, pioneiramente, havia sido levantado nos Parâmetros Curriculares Nacionais (PCN) de 1998, surgidos como diretrizes norteadoras da educação brasileira, cujo como objetivo é a manutenção do "princípio da base nacional comum" (BRASIL, 1998, p. 15-16).

Os PCNs representam um esforço para trabalhar a questão das diferenças, principalmente com a inserção do tema transversal Pluralidade Cultural, ainda que o enfoque privilegiado tenha sido organizado conforme a visão eurocentrista da história (BRASIL, 1998).

No próprio espaço jurídico, não há unanimidade quanto à discussão da diferença e, mais recentemente, quanto ao tratamento dos direitos das minorias. Bastará deslocar o olhar para o plano sociocultural, para o cotidiano, para ver o quanto os padrões de discriminação, preconceito e racismo são, ao mesmo tempo, recorrentes e denegados. Ainda que os próprios termos de racismo e preconceito tenham definições diversas, sabe-se que constituem ainda hoje dispositivos eficientes e atuantes, cuja lógica (também ela de classe e de gênero) tem lugar em diversos espaços individuais e coletivos, tanto na esfera pública quanto na privada.

Faz-se presente, inclusive no âmbito escolar que vem apresentando sérias dificuldades em trabalhar com a diferença, a diversidade e a desigualdade. Frequentemente, a questão da desigualdade e da diferença no espaço escolar foi considerada do ponto de vista puramente individual e centrada sobre a questão do desempenho escolar. Nesse sentido, notas, apreciações dos 
A CULTURA POPULAR | Heridan de Jesus G. P. Ferreira, Rayron Lennon C. Sousa e Wheriston S. Neris

docentes, taxas de repetência, evasão etc. dariam conta dos atributos que diziam respeito estritamente aos alunos, às suas vocações, apetências e competências para o estudo. Porém, desde pelo menos a década de 1960-70, e principalmente através dos ganhos da sociologia da educação francesa (BOURDIEU; PASSERON, 1992; BAUDELOT; ESTABLET, 1978; ALTHUSSER, 1985), sabe-se que a escola, ao contrário de ser democrática, meritocrática e equalizadora das diferenças, não apenas impõe os símbolos da cultura legítima (por meio de uma modalidade de violência dissimulada a que Pierre Bourdieu chamou de "violência simbólica") como também traveste em avaliação escolar um sistema de classificação inteiramente social. A escola adquire uma função central no sistema de reprodução social, encabeçando a reprodução de formas de distinções sociais anteriormente gestadas e garantidas no seio de um modo de dominação que era predominantemente orientado pela família.

Esta percepção motivou diversas pesquisas sobre o cotidiano escolar, tentando aprender o caráter difuso e mesmo a capilaridade de lógicas de dominação, poder e classificação social na escola. Aqui se encontram desde trabalhos sobre as representações formuladas pelas crianças (menos afeitas a dissimularem o padrão de exclusão de que são objeto), até mesmo aquelas sobre o currículo (MOREIRA; SILVA, 2002) e os materiais didáticos (OLIVA, 2003).

Desde então, são recorrentes falas como a de Perrenoud (1994), segundo o qual é importante elaborar um projeto pedagógico que atenda à própria diversidade que permeia a escola, ou como a de Tomaz Tadeu da Silva (2002), que também aponta para a necessidade de um currículo e uma pedagogia de caráter democrático, que deveria ter como primeira meta o reconhecimento dos diferentes posicionamentos sociais e dos repertórios culturais na sala de aula, reconhecendo as relações de poder que os perpassam. Nota-se, também, uma insuficiência de materiais que permitam o adequado tratamento da diferença e da diversidade em sala de aula. Bastará notar que, se por um lado já há disponíveis trabalhos que alicerçam a iniciativa da Lei $n^{0}$ 10.639/03, quanto aqueles mais diretamente associados à Lei $n^{0} 11.645 / 08$, sua divulgação ainda se apresenta bastante limitada, para dizer o mínimo.

Nessa perspectiva, a questão já não é somente a de identificar as matrizes ideológicas que permeiam os discursos da escola, do aluno e do professor, mas o de entender em que medida o próprio espaço escolar e os padrões de interdependência que lhes são específicos, ao contrário de equalizar as diferenças, exercem uma posição central entre os instrumentos de reprodução cultural dominante, inclusive naquelas situações mais permeadas de boa vontade ou disfarçadas por aparências afetuosas. O tratamento da diversidade cultural, nesse caso, passa pela compreensão de todo um conjunto de violências simbólicas de que a escola se faz porta-voz.

Essa compreensão é uma conquista contra a própria lógica de reprodução que impede um saudável diálogo em que a unidade assegure e favoreça a diversidade, e a diversidade se inscreva na unidade, como assinala Edgar Morin (2001, p. 57). Porém, se a sociologia da educação da década de 1960-70 identificou os vínculos inelutáveis entre escola e reprodução de habitus sociais, isso não significa que a escola, necessariamente, funcionou (ou funcionará) nesse sentido (LAHIRE, 2003).

Essa percepção não restringe o principal problema que ainda é o de tratar a diferença cultural, sem ceder aos abusos de sua desqualificação ou irreconhecimento, ou mesmo nos exageros de hiper-dimensionamento. Essa tendência se inscreve nos próprios usos e abusos de categorias como cultura negra, popular, raça, racismo, África, afro, cujas definições têm resultado do conflito entre intelectuais de diversas procedências (SANSONE, 2002). É por essa razão que se optou por colocar no título do projeto ${ }^{2}$ a ideia de reconstrução de conceitos, a partir do olhar educativo,

${ }^{2}$ O projeto de extensão desenvolvido em São Bernardo foi intitulado "LINGUAGENS E SABERES REGIONAIS: um olhar educativo sobre a questão racial." 
pois a ambiguidade do emprego das noções é acompanhada por uma certa confusão acerca de sua aplicabilidade e sobre a que se referem. É precisamente em vista disso que esta discussão toma partido de uma intervenção social suscitada, a partir de uma reflexão acadêmica e profunda sobre o que está em jogo, quando se discute a história e a cultura afro-indígena brasileira e, especialmente, que caminhos metodológicos devem ser trilhados, no sentido de efetivar a temática na sala de aula, reflexão esta que resultou na elaboração e aplicabilidade do projeto de extensão já mencionado.

Essa percepção toca no último ponto a ser considerado, o da necessidade de trabalhar questões que fazem parte do cotidiano da escola, especialmente da escola maranhense, como é o caso da cultura popular que tem fortes raízes no estado do Maranhão.

O foco da discussão não está na figura dos coordenadores, mas no processo dialógico-formativo que considera o estudante como construtor ativo de sua própria aprendizagem e realidade. A diretriz aqui buscada conduz-se pela ênfase no processo contínuo de desenvolvimento de autonomia profissional e intelectual do estudante (FREIRE, 1996) e da aprendizagem significativa.

\subsection{Do Desenvolvimento do Projeto}

No tocante ao projeto "LINGUAGENS E SABERES REGIONAIS: um olhar educativo sobre a questão racial", o cenário inicial não foi diferente, verificando-se certa dificuldade, especialmente dos profissionais das escolas onde o projeto foi desenvolvido, em discutir questões voltadas para o racismo, discriminação e preconceito para além do empírico e de modo articulado ao currículo escolar, o que fez com que se buscasse desenvolver ações que suscitassem na escola maior atenção para o tratamento do tema, nas diferentes áreas do conhecimento.

Outro ponto importante detectado foi o fato de não haver material didático específico para que a temática fosse trabalhada de forma transversal, conforme preconiza a Lei $n^{\circ} 11.645 / 08$, o que fez com que se pensasse na cultura popular, considerando que a região agrega diferentes manifestações culturais, mesmo que se tenha identificado que algumas delas estão prestes a desaparecer, tais como o bumba meu boi ${ }^{3}$ e o tambor de crioula ${ }^{4}$.

Observado esse aspecto, o projeto desdobrou-se em oficinas, sendo trabalhados os aspectos voltados para a aplicabilidade do tema nas diferentes áreas, fazendo-se algumas inserções sobre determinados elementos da cultura popular maranhense, tais como o bumba meu boi, o tambor de crioula, entre outros.

\section{4 | A CULTURA POPULAR COMO ELEMENTO PARA INSERÇÃO DA LEI Nº 11.645/08 NO CURRÍCULO ESCOLAR}

Estudos diversos, tais como os de Moreira e Silva (2002) e Tomaz Tadeu da Silva (2002), entre outros, apontam para a necessidade de um currículo que de fato articule teoria e prática, fugindo das amarras de um ensino fragmentado e abstrato, para trabalhar os conteúdos de forma concatenada, a partir da realidade vivenciada pela comunidade local, favorecendo a aprendizagem significativa.

\footnotetext{
${ }^{3} \mathrm{O}$ Bumba meu boi é uma manifestação cultural que se desenvolve em torno de um boizinho de brinquedo e o desejo de Catirina, negra grávida que deseja comer a língua do boi, fazendo com que seu marido, o Negro Chico, mate o boi mais bonito da fazenda. Descoberto o 'crime', são chamados os índios, para que, em um ritual de pajelança (religião afro-indígena), o boi seja ressuscitado.

${ }^{4} \mathrm{O}$ Tambor de Crioula é uma dança circular, em que um grupo de mulheres (coreiras) dança em frente a uma parelha de tambor. Embora não seja em si uma religião, observa-se na manifestação um viés com a religiosidade, pois muitos tambores têm por razão uma promessa feita a um santo.
} 
Ainda que se possa observar que muitos professores já estejam trabalhando nas salas de aula conteúdos relacionados à inserção da história e cultura afro-brasileira e indígena, nas diferentes áreas do conhecimento, tais como: Ensino Religioso, História, Geografia, Literatura entre outras, verifica-se que ainda não ocorreu uma mudança positiva e substancial. Muitos educadores atribuem à falta de uma política de formação de professores que propicie, não apenas os subsídios relacionados aos conteúdos propriamente ditos, mas também e, principalmente, o ponto de vista metodológico, esbarrando ainda na ausência de material didático adequado para tratamento do tema (OLIVA, 2003), a qual vem sendo uma das principais justificativas para trabalhar o tema.

No tocante à cultura popular, especialmente no que diz respeito a sua inserção na educação formal, Silva (2009, p. 1) afirma:

\begin{abstract}
No Brasil, o debate sobre as relações entre cultura popular e escola pública surge nos anos 50 e 60, a partir do método Paulo Freire e de outros movimentos de educação, aparecendo o que se denominou educação popular. Educação esta que valoriza, sobretudo, a cultura que estaria, inicialmente, destinada ao povo, referindo-se nesta perspectiva à valorização desta cultura como meio de lutar contra a discriminação dos seus produtores e reforçar os grupos sociais que tem sua participação restrita na sociedade.
\end{abstract}

Verifica-se que a cultura popular se constitui, além da integração de determinados temas, uma forma de resistência contra o preconceito e estigmatização, ainda que seja, muitas vezes, considerada inferior, no âmbito do saber formal.

Freire (1963, p. 11) aponta para a necessidade da articulação entre a cultura popular e a educação, comentando que "um outro dado que partíamos era o de que a educação trava uma relação dialética com a cultura. Desta forma, a nossa ciência educativa não poderia sobrepor-se à realidade contextual nossa." Tal premissa demonstra que a cultura popular é o pressuposto para o diálogo com a educação, diálogo este permeado de significações que deve ser considerado pela escola ${ }^{5}$.

Nesse contexto, insere-se a cultura popular maranhense, enquanto forma de inserção da história e cultura africana, afro-brasileira e indígena no currículo escolar, conforme o que dispõe a Lei $n^{\circ} 11.645 / 08$.

Segundo Morin (2001, p. 56),

[...] a cultura é constituída pelo conjunto dos saberes, fazeres, regras, normas, proibições, estratégias, crenças, ideias, valores, mitos, que se transmite de geração em geração, se reproduz em cada indivíduo, controla a existência da sociedade e mantém a complexidade psicológica e social. Não sociedade humana, arcaica ou moderna, desprovida de cultura, mas cada cultura é singular. Assim, sempre existe a cultura nas culturas, mas a cultura existe apenas por meio das culturas.

Observa-se, assim, a importância da cultura no âmbito da educação formal. Silva (2009, p. 2) afirma que "discutir a escola e a diversidade cultural significa compreendê-la na ótica da cultura, sob um olhar mais denso, que leva em conta a dimensão do dinamismo."

A despeito disso, no que concerne ao estado do Maranhão, conhecido pela sua diversidade cultural, pouco se observa em sala de aula a cultura maranhense trabalhada e explorada no contexto das diferentes disciplinas, ficando os professores, muitas vezes, atrelados a um rol de conteúdos que não considera tal diversidade (FERREIRA; SILVA FILHO, 2011).

\footnotetext{
${ }^{5}$ Ressalta-se que o termo escola por adotado neste trabalho se refere ao ambiente escolar em sua totalidade, ou seja, desde a escola de educação infantil e básica até as instituições de nível superior.
} 
Verifica-se, assim, que a escola pouco privilegia os conhecimentos que fazem parte da vida do educando, deixando de aproveitar toda uma gama de possibilidades que favorecem o aluno na construção de saberes, caso seja posto em contato com manifestações culturais, como, por exemplo, o bumba meu boi, o tambor de crioula, o reggae, a festa do divino ${ }^{6}$, entre outras manifestações da cultura popular maranhense, manifestações que agregam, em seu contexto, os aspectos da história e da cultura afro-brasileira e indígena, constituindo-se alternativas para discussão da temática de forma articulada e transversal, nas diferentes áreas de conhecimento, conforme preconizam os PCN (BRASIL, 1998).

Tais manifestações, à guisa de compreendê-las, mesmo que de modo sucinto, são, em sua maioria, danças circulares, como é o caso do bumba meu boi e do tambor de crioula. Possuem viés religioso, como é o caso do bumba meu boi, festa do divino e tambor de crioula, porém seus traços mais marcantes são as raízes afro-brasileiras e indígenas, o que justifica sua inserção na sala de aula. São manifestações que possibilitam a interação entre os sujeitos, pelos seus aspectos culturais.

Cabe ressaltar que a cultura foi um dos aspectos introdutórios do método freireano que discorre o seguinte:

\begin{abstract}
Pareceu-nos, então, que o caminho seria levarmos o analfabeto, através de reduções, ao conceito antropológico de cultura. O papel ativo do homem em sua e com sua realidade. $\mathrm{O}$ sentido da mediação que tem a natureza para as relações e comunicações dos homens. A cultura como acrescentamento que o homem faz ao mundo que ele não fez. A cultura como resultado de seu trabalho. De seu esforço criador e recriador. O homem, afinal, no mundo e com o mundo, como sujeito e não como objeto. [...] descobrir-se-ia criticamente agora, como fazedor desse mundo da cultura. Descobriria que ele, como o letrado, ambos têm um ímpeto de criação e recriação. Descobriria que tanto é cultura um boneco de barro feito pelos artistas, seus irmãos do povo, como também é a obra de um grande escultor, de um grande pintor ou músico. Que cultura é a poesia dos poetas letrados do seu país, como também a poesia do seu cancioneiro popular. Que cultura são as formas de comportar-se. Que cultura é toda criação humana. (FREIRE, 1963, p. 17).
\end{abstract}

Considera-se, assim, que a cultura se constitui o instrumento para o intercâmbio entre diferentes saberes que propicia ao aluno o contato e interação com dimensões que lhes são desconhecidas. O professor deve ter atitude para transpor os muros da escola, expondo o aluno a uma realidade em que ele possa alcançar o conhecimento global dos conteúdos, fugindo da fragmentação proposta por muitos currículos ainda trabalhados em muitas escolas do país (MORIN, 2002).

Os elementos da cultura popular podem ser bastante eficazes para os alunos conhecerem realidades do seu próprio estado, o Maranhão, fazendo uma correlação com outras realidades, ou seja, partindo do local para o global, o que pode ser possibilitado por meio de um trabalho interdisciplinar. Segundo Barbosa (1991, p. 65), o caminho para se alcançar esse fim, como se pode observar, "É preciso entender, também, que o conhecimento interdisciplinar não se restringe a sala de aula, mas ultrapassa os limites do saber escolar e se fortalece na medida em que ganha a amplitude da vida social."

Trabalhar, entretanto, de forma interdisciplinar não é tarefa muito simples, haja vista ir além de questões relacionadas às diferentes áreas de conhecimento e seus conteúdos. Deve-se considerar que a problemática diz respeito às diferentes concepções que os educadores possam ter,

\footnotetext{
${ }^{6}$ A cultura popular maranhense, no que diz respeito, de modo mais específico, às manifestações apontadas no texto (bumba meu boi, tambor de crioula, reggae e festa do divino), por meio das diferentes linguagens a ela intrínsecas, permite a exploração do tema história e cultura afro-brasileira e indígena, no currículo escolar.
} 
A CULTURA POPULAR | Heridan de Jesus G. P. Ferreira, Rayron Lennon C. Sousa e Wheriston S. Neris

tanto sobre a cultura popular propriamente dita, quanto sobre a concepção do processo ensino-aprendizagem. Essas concepções, muitas vezes, terminam amarrando o processo, de forma a impossibilitar qualquer tentativa de superação da fragmentação do saber, tornando difícil a construção de novos saberes.

Considera-se ainda, que algumas comunidades, mesmo sendo locais onde a cultura aflora com muita facilidade, por serem tradicionais redutos de manifestações da cultura popular, sofrem com o preconceito de se achar que o que é por elas realizado não pode servir para a construção do saber formal, ou seja, não é adequado para a realidade de sala de aula, exceto quando se tratar de datas pontuais, como as datas comemorativas que integram o calendário escolar.

Nesse contexto, o professor exerce um papel fundamental. Seu trabalho, ainda que, muitas vezes, silencioso e solitário, é um trabalho que, na concepção de Barbosa (1991), constitui-se um fazer em que qualquer iniciativa de criação do saber sofre inibições pela ausência de estímulos.

É importante lembrar que a escola é o local onde todas as questões acerca do distante, do oculto, do novo devem aflorar, ou seja, a escola é um espaço democrático onde as manifestações culturais podem ser empregadas para se poder chegar a novos entendimentos ou à compreensão de outros saberes.

O educando deve transpor os muros da escola, com o professor mostrando-lhe que, como aluno, pode ter um envolvimento com o mundo fora dela e que é através dessa atitude que ele vivenciará a modelação de um novo saber, pelas relações sociais.

São as relações sociais que verdadeiramente educam, isto é, formam, produzem os indivíduos em suas realidades singulares e mais profundas. Nenhum individuo nasce homem. Portanto, a educação tem um sentido mais amplo, é o processo de produção de homens num determinado momento histórico. (DAYRELL, 1992, p. 2).

A escola precisa despertar para a necessidade de educar seus cidadãos para fazer leituras contextualizadas do mundo que os abriga, forçando assim seus formandos a reconstruírem suas concepções de si mesmos e do mundo em que vivem, tendo a cultura popular como forte aliado.

No que diz respeito à abordagem metodológica para inserção do ensino de história e cultura africana e indígena no currículo escolar, faz-se necessário que sejam consideradas as multiplicidades culturais, étnicas, sociais, econômicas, dentre outras, pois o educando, ao verificar que o trabalho desenvolvido nas diferentes áreas de conhecimento possui relação com temas e assuntos que permeiam seu cotidiano, fará as associações necessárias para, a partir da compreensão da cultura local; compreender o mundo, usando como ferramenta a cultura popular.

\section{5 | CONSIDERAÇÕES FINAIS}

O currículo adotado pelas escolas brasileiras, historicamente, tem desconsiderado aspectos que impingem significado às classes menos favorecidas, não oportunizando uma maior aproximação entre os sujeitos que ensinam com aqueles que aprendem e seus contextos sociais.

Observa-se, ainda, que esse currículo pouco evidencia as diferenças entre os sujeitos, diferenças estas que, se trabalhadas adequadamente, focalizam a diversidade no espaço escolar, possibilitando o desenvolvimento de diferentes sensos, fundamentais para o aprendizado e convívio entre as pessoas.

Nas últimas décadas, como fruto das lutas de segmentos da sociedade civil organizada, de modo mais específico do movimento negro organizado, vêm ocorrendo mudanças no currículo trabalhado nas escolas brasileiras, especialmente a partir das Leis de $n^{\circ} 10.639 / 03$ e $n^{\circ} 11.645 / 08$, modificando, assim, a educação formal que, via de regra, esteve associada ao fazer científico e, 
A CULTURA POPULAR | Heridan de Jesus G. P. Ferreira, Rayron Lennon C. Sousa e Wheriston S. Neris

muitas vezes, estigmatiza a cultura popular, que reiteradamente vem sendo considerada pela escola enquanto um saber à parte, sem um viés científico.

A visibilidade da cultura popular na escola geralmente ocorre nos períodos de festas e datas comemorativas, sem estar inserida no currículo trabalhado ao longo das atividades escolares, durante o ano letivo.

As Leis $n^{\circ} 10.639 / 03$ e $n^{\circ} 11.645 / 08$, além de modificar a atual LDB suscitaram uma reflexão sobre o que vem sendo ensinado e aprendido nas escolas, fazendo com que se buscassem materiais e metodologias para inserção da história e cultura africana e indígena no currículo escolar.

A cultura popular, de modo geral, mesmo sendo considerada, no que diz respeito aos saberes e vivências que caracterizam os diferentes grupos sociais, esteve, na maioria das vezes, atrelada a um saber informal, sendo assim, desprivilegiada pela escola.

A valorização e o respeito pela cultura, folclore e tradições locais devem permear o ensino em todas as áreas de conhecimento, especialmente no que concerne ao caso do Maranhão, local onde foi desenvolvido o projeto descrito neste artigo. Desse modo, bumba meu boi, tambor de crioula; cacuriá; festa do Divino, entre outras manifestações que se constituem em patrimônio imaterial do estado do Maranhão, tornam-se importantes aliados do saber formal, possibilitando um diálogo inter e multidisciplinar entre as diferentes áreas de conhecimento.

Os conteúdos trabalhados nas diferentes áreas de conhecimento devem ser abordados, tanto no contexto da cultura local quanto em níveis regionais, nacionais e internacionais.

Um exemplo disso está na abordagem das heranças de outras línguas para a formação da língua falada no Brasil, que se materializam no léxico que permeia os discursos das toadas do bumba meu boi ou nas ladainhas do tambor de crioula.

O conhecimento matemático pode ser abordado de forma significativa, ao se trabalhar conceitos de números, funções, entre outros conteúdos pertinentes à Matemática que se materializam ao olhar mais atento para as brincadeiras, como são conhecidos esses elementos da cultura popular maranhense.

No campo da Geografia, as relações sociais que caracterizam tanto o Brasil como a África, assim como a compreensão da origem de aspectos da cultura popular, enquanto herança cultural das diferentes raças que formaram o povo brasileiro.

A compreensão da arte como cultura, sua estética presente nos artefatos utilizados nas manifestações, tais como as máscaras usadas no auto do bumba meu boi, o colorido das saias das coreiras (dançarinas) do tambor de crioula, a musicalidade que caracteriza todas as manifestações, entre outros elementos artísticos a ela pertinentes.

O olhar pedagógico sobre os elementos da cultura popular maranhense possibilita a efetivação da Lei $n^{\circ}$ 11.645/08, como também favorece a compreensão do educando, em relação às contribuições de diferentes povos, fazendo com que ele construa novos conhecimentos e articule os saberes construídos formalmente pela escola com aqueles que permeiam a cultura popular. 


\section{Referências}

ALTHUSSER, L. Os aparelhos ideológicos do estado: nota sobre os aparelhos ideológicos do estado. 3. ed. Rio de Janeiro: Graal, 1985.

ARROYO, Miguel G. Currículo: território em disputa. RJ: Vozes, 2011.

BANDEIRA, L.; BATISTA, A. S. Preconceito e discriminação como expressões de violência. Revista Estudos feministas, jan. 2002.

BARDIN, L. Análise de conteúdo. São Paulo: Edições 70, 2011.

BAUDELOT, C.; ESTABLET, R. La escuela capitalista em Francia. Madrid: Siglo XXI, 1978.

BOURDIEU, P.; PASSERON, J. C. A reprodução: elementos para uma teoria do sistema de ensino. 3. ed. Rio de Janeiro: [s.n.], 1992.

BARBOSA, D. A conquista do educador popular e a interdisciplinaridade do conhecimento. São Paulo: Cortez, 1991.

BRASIL. Lei no 10.639, de 9 de janeiro de 2003. Altera a Lei no 9.394, de 20 de dezembro de 1996, que estabelece as diretrizes e bases da educação nacional, para incluir no currículo oficial da Rede de Ensino a obrigatoriedade da temática "História e Cultura Afro-Brasileira", e dá outras providências. Diário Oficial da União, Brasília, DF, 10 jan. 2003.

. Lei no 11.645, de 10 de março de 2008. Altera a Lei no 9.394, de 20 de dezembro de 1996, modificada pela Lei no 10.639, de 9 de janeiro de 2003, que estabelece as diretrizes e bases da educação nacional, para incluir no currículo oficial da rede de ensino a obrigatoriedade da temática "História e Cultura Afro-Brasileira e Indígena". Diário Oficial da União, Brasília, DF, 11 mar. 2008.

. Lei no 9.394, de 20 de dezembro de 1996.

Estabelece as diretrizes e bases da educação nacional. Diário Oficial da União, Brasília, DF, 23 dez. 1996.

. Lei $n^{\circ} 1.390$, de 3 de julho de 1951. Inclui entre as contravenções penais a prática de atos resultantes de preconceitos de raça ou de cor. Diário Oficial da União, Brasília, DF, 10 jul 1951.

Ministério da Educação. Secretaria de Educação Continuada, Alfabetização e Diversidade. Orientações e ações para a educação das relações étnico-raciais. Brasília, DF: SECAD, 2006.
. Ministério da Educação e do Desporto. Secretaria de Educação Fundamental. Parâmetros Curriculares Nacionais: terceiro e quarto ciclos do ensino fundamental: introdução aos parâmetros curriculares nacionais. Brasília, DF: MEC; SEF, 1998.

CUNHA JÚNIOR, H. As estratégias de combate ao racismo: movimentos negros na escola, na universidade e no pensamento brasileiro. In: MUNANGA, K. (Org.). Estratégias e políticas de combate à discriminação racial. São Paulo: Edusp, 1996. p. 147-156.

DAYRELL, J. T. A educação do aluno trabalhador: uma abordagem alternativa. Educação em Revista, Belo Horizonte, n. 15, p. 21-29, jun. 1992.

DOSSE, F. O império do sentido: a humanização das ciências sociais. Bauru: EDUSC, 2003.

FERREIRA, H. de J. G. P.; SILVA FILHO, M. N. dos R. O bumba meu boi no currículo escolar. In: CUNHA, A.

S. de A. Construindo quilombos, desconstruindo mitos: a lei 10.639 na sala de aula. São Luís: Setagraf, 2011.

FREIRE, Paulo. Conscientização e alfabetização: uma nova visão do processo. Revista de Cultura da Universidade de Recife. n 4, abr./jun., 1963.

\section{Pedagogia da autonomia: saberes}

necessários à prática educativa. São Paulo: $\mathrm{Paz} \mathrm{e}$ Terra, 1996.

HASENBALG, C. A.; SILVA, N. do V. Raça e oportunidades educacionais no Brasil. Estudos Afro-Asiáticos, Rio de Janeiro, n. 18, p. 73-91, 1990.

LAHIRE, B. Crenças coletivas e desigualdades culturais. Educ. Soc. Campinas, v. 24, n. 84, p. 983-995, set. 2003.

MINAYO, M. C. de S. (Org.). Pesquisa social: teoria, método e criatividade. 29. ed. Petrópolis: Vozes, 2010.

MOREIRA, A. f.; SILVA, T. T. Currículo, cultura e sociedade. 6. ed. São Paulo: Cortez, 2002.

MORIN, Edgar. Os sete saberes necessários à educação do futuro. São Paulo: Cortez, 2001.

. O método V: a humanidade da humanidade. Porto Alegre: Sulina, 2002.

OLIVA, A. R. A história da África nos bancos escolares: representações e imprecisões na literatura didática. Estudos Afro-Asiáticos, ano 25, n. 3, p. 421-461, 2003. 
A CULTURA POPULAR | Heridan de Jesus G. P. Ferreira, Rayron Lennon C. Sousa e Wheriston S. Neris

PERRENOUD, P. Práticas pedagógicas, profissão docente e formação: perspectivas sociológicas. Lisboa, Portugal: Dom Quixote, 1994.

SACRISTÁN, J. Gimeno. Currículo e diversidade cultural. In: SILVA, Tomaz Tadeu da. (Org). Alienígenas na sala de aula: uma introdução aos estudos culturais em educação. Petrópolis: Vozes, 1995.

SANSONE, L. "Da África ao afro: uso e abuso da África entre os intelectuais e na cultura popular brasileira durante o século XX". Afro-Ásia, v. 27, p. 249-269, 2002.
SANTOS, G. W. Modificando a escola através da educação ambiental: construindo a agenda 21 escolar. EEB Dom Pio de Freitas. 2006

SILVA, Tomaz Tadeu da. Documentos de identidade: uma introdução ás teorias do currículo. 2. ed. Belo Horizonte: Autêntica, 2002.

(Org.). Identidade e diferença: a perspectiva dos estudos culturais. 9 ed. Petrópolis, RJ: Vozes, 2009. 